\title{
Jacob's disease secondary to coronoid process osteochondroma. A case report
}

\author{
Manel Coll-Anglada ${ }^{1}$, Julio Acero-Sanz ${ }^{2}$, Irene Vila-Masana ${ }^{1}$, Carlos Navarro-Cuéllar ${ }^{2}$, Santiago Ochandia- \\ no-Caycoia ${ }^{2}$, Javier López de-Atalaya ${ }^{2}$, Carlos Navarro-Vila ${ }^{3}$
}

\footnotetext{
${ }^{1}$ Resident. Department of Oral and Maxillofacial Surgery. HGU Gregorio Marañón. Madrid. Spain

${ }^{2}$ Staff physician. Department of Oral and Maxillofacial Surgery. HGU Gregorio Marañón. Spain

${ }^{3}$ Department Chief. Department of Oral and Maxillofacial Surgery. HGU Gregorio Marañón. Spain
}

Correspondence:

C/Flandes $n^{\circ} 4$ portal B piso $2^{\circ} B$

28030 Madrid. Spain

mcollang@yahoo.es

Coll-Anglada M, Acero-Sanz J, Vila-Masana I, Navarro-Cuéllar C, Ochandiano-Caycoia S, López de-Atalaya J, Navarro-Vila C. Jacob's disease secondary to coronoid process osteochondroma. A case report. Med Oral Patol Oral Cir Bucal. 2011 Sep 1;16 (6):e708-10.

Received: 08/02/2010

Accepted: 15/04/2010

http://www.medicinaoral.com/medoralfree01/v16i6/medoralv16i6p708.pdf

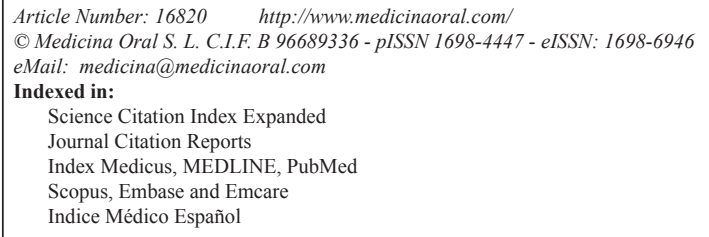

\begin{abstract}
The formation of a new joint between a pathologically elongated coronoid process and the body of the malar homolateral bone is known as Jacob's disease.

Coronoid process hyperplasia was first described in 1853 by Von Langenbeck, and it was not until 1899 when Oscar Jacob described the disease that it was named after him. Jacobs's disease is an uncommon entity with only a few documented cases in the literature. The condition first manifests with progressive limitation of mouth opening and facial asymmetry. Pain is uncommon and it mainly affects young patients. Different factors have been postulated as possible causes, including temporal muscle hyperactivity, previous trauma, chronic disc displacement of the ipsilateral temporomandibular joint, endocrine stimuli, and genetic alterations. Definitive diagnosis is by histopathology and it is necessary to confirm bone hyperplasia, the presence of cartilage and synovial capsule forming the new joint between the malar bone and the coronoid process. We report a 52-year-old woman patient with a history of childhood trauma in the right preauricular region. She came to our department with a 2-year history of progressive limitation of mouth opening. Computed tomography (CT) revealed a right coronoid process elongation, in contact with the homolateral malar bone, causing it to deform. Surgery with general anesthesia was performed using an intraoral vestibular approach. Histopathology confirmed the diagnoses of Jacob's disease.
\end{abstract}

Key words: Jacob's disease, osteochondroma coronoid process, coronoid process hyperplasia, coronoidectomy. 


\section{Introduction}

Jacob's disease is described as the formation of a new joint between an elongated coronoid process and the body of the malar bone. It is an uncommon entity that mainly affects young males. Although predominantly unilateral, bilateral cases have been reported (1).

The pathogenesis of this disease remains uncertain, and proposed causes include temporal muscle hyperactivity (2), previous injury, chronic disc displacement of the ipsilateral temporomandibular joint (TMJ), endocrine stimuli, and genetic alterations (3-7).

The condition first manifests with progressive limitation of mouth opening and deviation from the midline towards the affected side (1), accompanied in most cases by midface asymmetry resulting from a deformed malar bone. Pain is uncommon (1).

Most authors agree that the treatment of choice is intraoral coronoidectomy (1). Other therapeutic options described in the literature are the coronal (8) and submandibular (9) approaches. We present a new case of Jacob's disease, and discuss its clinical characteristics, diagnosis, and treatment.

\section{Case Description}

A 52-year-old woman with a history of childhood trauma in the right preauricular region (accidental fall) came to our department with a $2 \frac{1}{2}$-year history of progressive limitation of mouth opening (Fig. 1). She did not report pain or other symptoms. Physical examination revealed maximum mouth opening (MMO) of $8 \mathrm{~mm}$ with a mandibular deviation to the right side. She also presented facial asymmetry in the right malar region, more accentuated during mouth opening. There was no involvement of the temporomandibular joint on the right or left side. Additional tests such as Waters projection and a panoramic radiograph revealed an abnormal elongation of the right coronoid process overlapping the ipsilateral malar bone. These findings led us to perform a computed tomography scan, which confirmed coronoid process hyperplasia and accommodation of the distal coronoid process on the inside of the malar bone (Fig. 2).

Surgery was performed under general anesthesia using an intraoral vestibular approach. A joint structure was observed between the coronoid process hyperplasied and the inner surface of the malar bone, and hyaline cartilage was visible between the two joint surfaces. We performed right coronoidectomy (Fig. 3) and remodeled the malar bone. In the immediate postoperative period, we obtained a 47-mm MMO. Histopathology revealed osteochondroma. Treatment was supplemented with intensive physiotherapy for three months. Six months after surgery, the patient has a 41-mm MMO and persistent rightward lateral deviation during mouth opening. The aesthetic results are satisfactory, with improvement of facial asymmetry.

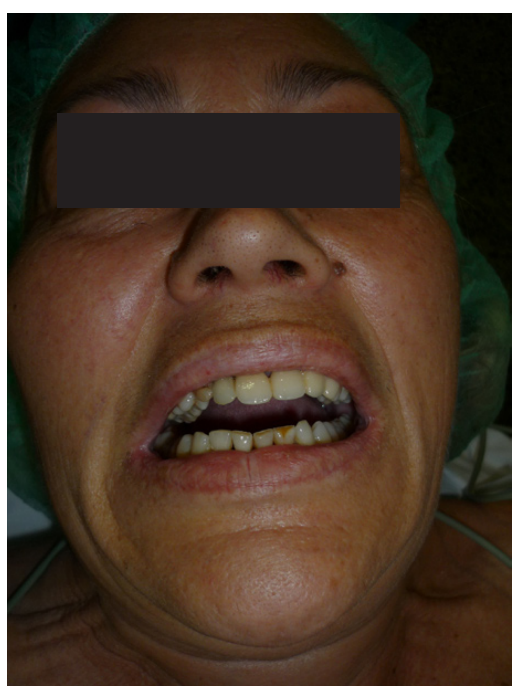

Fig. 1. Physical examination revealed maximum opening of $8 \mathrm{~mm}$ with a mandibular deviation to the right side.

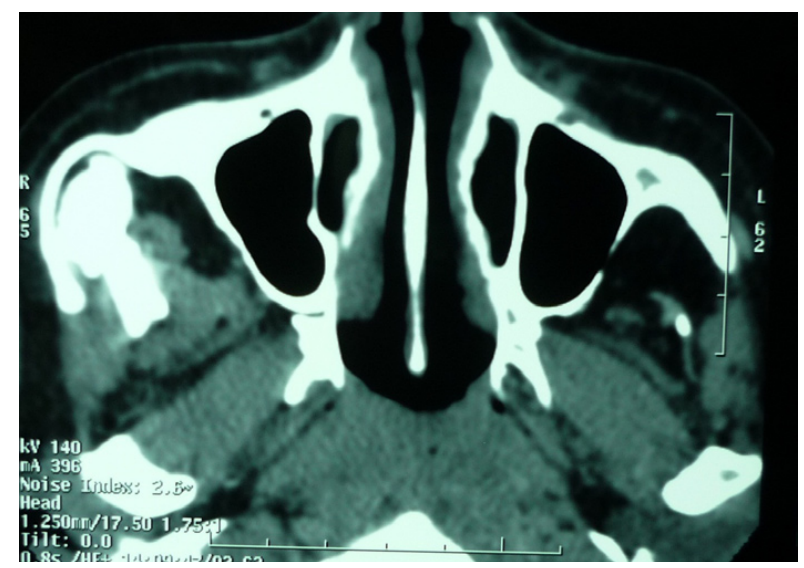

Fig. 2. Computed tomography image showing right coronoid process hyperplasia in contact with the homolateral malar bone, causing it to deform.

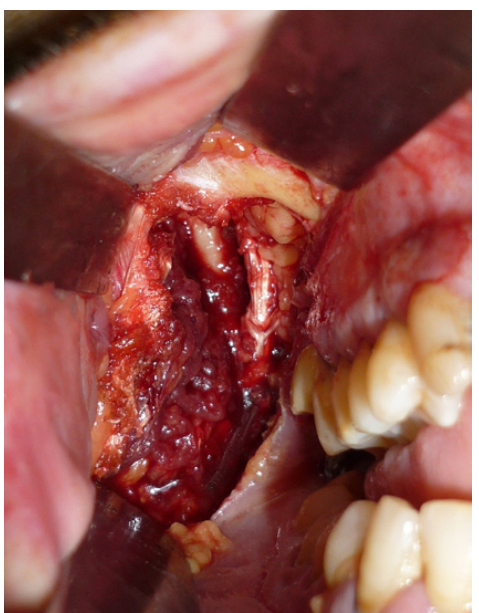

Fig. 3. Coronoidectomy. Intraoral approach. 


\section{Discussion}

Jacob's disease is an uncommon condition, with few reports in the literature. The proposed causes include temporal muscle hyperactivity, which could lead to increased vascular supply and reactive elongation of the coronoid process (2). Other proposed causes are previous trauma (as in our patient), chronic disc displacement, endocrine disruptions, and genetic abnormalities (3-7).

Patients with Jacob's disease complain of progressive limitation of mouth opening. They also present midline deviation toward the affected side during mouth opening (10) and, in some cases, a prominent ipsilateral malar bone like our patient. Pain is uncommon, even though it can arise from chronic disc displacement of the ipsilateral temporomandibular joint $(1,6,10)$.

All patients should undergo conventional radiology, although tuned-aperture computed tomography is recommended in cases of suspected coronoid process hyperplasia (1), as it enables us to confirm the diagnosis and plan surgery. The most informative test for diagnosis and planning is 3D-computed tomography $(8,11)$, which is now available in most centers.

Definitive diagnosis is by histopathology. Coronoid process hyperplasia is not always synonymous with Jacob's disease, in which the coronoid process forms a joint with the inner surface of the malar bone and is accompanied by cartilaginous structures and the formation of a synovial capsule $(1,8,10)$. Depending on the ratio of bone to cartilage, the diagnosis may be osteochondroma, osteoma, exostosis, or hyperplasia. In our patient, the lesion of the coronoid process was an osteochondroma. Histopathology confirmed the presence of hyaline structures and remnants of the synovial capsule, thus confirming the diagnosis of Jacob's disease.

Coronoidectomy is the standard treatment. Most authors agree that the intraoral approach performed in our patient is the most suitable, as it prevents facial nerve injury and scarring (12). Extraoral approaches, as described in the literature, are submandibular (9) and coronal (8). The latter is advised in cases where the coronoid process is too elongated to be resected intraorally and in cases of concomitant temporomandibular involvement requiring surgery (1). Surgery should be complemented by physical therapy to increase the chances of success and stable results over time $(8,13)$.

\section{References}

References with links to Crossref - DOI

1. Escuder i de la Torre O, Vert Klok E, Marí i Roig A, Mommaerts MY, Pericot I Ayats J. Jacob's disease: report of two cases and review of the literature. J Craniomaxillofac Surg. 2001;29:372-6.

2. Isberg A, Isacsson G, Nah KS. Mandibular coronoid process locking: a prospective study of frequency and association with internal derangement of the temporomandibular joint. Oral Surg Oral Med Oral Pathol. 1987;63:275-9.
3. McLoughlin PM, Hopper C, Bowley NB. Hyperplasia of the mandibular coronoid process: an analysis of 31 cases and a review of the literature. J Oral Maxillofac Surg. 1995;53:250-5.

4. Shackelford RT, Brown WH. Restricted jaw motion due to osteochondroma of the coronoid process. J Bone Joint Surg Am. 1949;31A:107-14.

5. Tucker MR, Guilford WB, Howard CW. Coronoid process hyperplasia causing restricted opening and facial asymmetry. Oral Surg Oral Med Oral Pathol. 1984;58:130-2.

6. Smyth AG, Wake MJ. Recurrent bilateral coronoid hyperplasia: an unusual case. Br J Oral Maxillofac Surg. 1994;32:100-4.

7. Praal FR. Limitation of mandibular movement due to bilateral mandibular coronoid process enlargement. J Oral Maxillofac Surg. 1984;42:534-6.

8. Hernández-Alfaro F, Escuder O, Marco V. Joint formation between an osteochondroma of the coronoid process and the zygomatic arch (Jacob disease): report of case and review of literature. J Oral Maxillofac Surg. 2000;58:227-32.

9. Ostrofsky MK, Lownie JF. Zygomatico-coronoid ankylosis. J Oral Surg. 1977;35:752-4.

10. Capote A, Rodríguez FJ, Blasco A, Muñoz MF. Jacob's disease associated with temporomandibular joint dysfunction: a case report. Med Oral Patol Oral Cir Bucal. 2005;10:210-4.

11. Takahashi A, Hao-Zong W, Murakami S, Kondoh H, Fujishita M, Fuchihata H. Diagnosis of coronoid process hyperplasia by threedimensional computed tomographic imaging. Dentomaxillofac Radiol. 1993;22:149-54.

12. Emekli U, Aslan A, Onel D, Cizmeci O, Demiryont M. Osteochondroma of the coronoid process (Jacob's disease). J Oral Maxillofac Surg. 2002;60:1354-6.

13. Gerbino G, Bianchi SD, Bernardi M, Berrone S. Hyperplasia of the mandibular coronoid process: long-term follow-up after coronoidotomy. J Craniomaxillofac Surg. 1997;25:169-73. 